Disponível em:

http://editora.unoesc.edu.br/index.php/race

RACE, Joaçaba, v. 17, n. 2, p. 695-732, maio/ago. 2018

\title{
PROGRAMAS DE PÓS-GRADUAÇÃO EM CONTABILIDADE: SEMELHANÇAS E DIFERENÇAS DA PRODUÇÃO BIBLIOGRÁFICA
}

Graduate program in Accounting: similarities and differences of bibliographic production

Sandro Vieira Soares

E-mail: sandrovs@usp.br

Doutor em Controladoria e Contabilidade pela Universidade de São Paulo; Pós-doutorando em Administração pela Universidade do Sul de Santa Catarina; Professor no Centro Universitário Municipal de São José. Endereço para contato: Rua Adolfo Melo, 34, 88015-090, Centro, Florianópolis, Santa Catarina, Brasil.

Victor Pereira Silva

E-mail: viictor_pereira@hotmail.com Bacharel em Ciências Contábeis pela Universidade Federal da Paraíba; Chefe de Gabinete da Controladoria Geral do Município de João Pessoa.

\section{Silvia Pereira de Castro Casa Nova}

E-mail: silvianova@usp.br

Pós-doutora pela University of Minnesota e pela Fundação Getúlio Vargas; Doutora em Controladoria e Contabilidade pela Universidade de São Paulo; Professora Titular no Departamento de Contabilidade e Atuária na Faculdade de Economia, Administração e Contabilidade da Universidade de São Paulo.

Alan Diógenes Góis

E-mail: alandgois@hotmail.com

Doutor em Controladoria e Contabilidade pela Universidade de São Paulo; Mestre em Administração e Controladoria pela Universidade Federal do Ceará; Professor no Centro Universitário das Faculdades Metropolitanas Unidas.

Artigo recebido em 05 de fevereiro de 2018. Aceito em 12 de julho de 2018. 


\section{Resumo}

Havia no Brasil, durante o triênio 2010-2012, 17 programas de pós-graduação stricto sensu acadêmicos em Contabilidade e Controladoria, espalhados por quatro regiões do Brasil e por quatro níveis de conceitos da Capes. Juntos, docentes e discentes desses programas publicaram mais de dois mil artigos em periódicos. A questão que norteou esta pesquisa foi: como se agrupam os programas de pós-graduação em Contabilidade, de acordo com as características das publicações veiculadas em periódicos, no período de 2010 a 2012? O objetivo com esta pesquisa foi simular os diversos agrupamentos desses programas, utilizando a análise de cluster. Para isso, foram feitas simulações usando cinco métodos de agrupamento, com três medidas de distância sobre cinco variáveis propostas por Soares e Múrcia (2016). Foi possível concluir que, dependendo da medida de distância utilizada, muda a disposição dos clusters dos programas. Além disso, percebeu-se que o método "vizinhos mais próximos” gera clusters mais difíceis de serem observados. Por fim, detectou-se a associação recorrente entre alguns programas, como o da UFPR e da Unisinos, assim como da FURB e da UFSC. Desse modo, concluiu-se que os programas do Sul do País apresentam características semelhantes quanto à publicação. A USP se destacou por se isolar dos outros programas. Soares e Casa Nova (2015) já demonstraram haver indicativos concordantes com esses resultados. Neste trabalho avança-se na discussão do uso de indicadores da produção bibliográfica para a avaliação da qualidade de programas de pós-graduação. É argumento dos autores deste trabalho que o sistema segue uma racionalidade focada em indicadores de produtos, e que pode afastar docentes e discentes da concentração de esforços no processo de pesquisa.

Palavras-chave: Programas de pós-graduação. Contabilidade. Publicações.

\section{Abstract}

During the triennium 2010-2012 there were in Brazil seventeen academic stricto sensu graduate programs in Accounting and Controllership spread across four regions of Brazil and across four levels of concepts of Capes. Together, teachers and students of these programs have published more than two thousand papers in journals. The question that guides this research is: How are graduate programs in Accounting grouped according to the characteristics of their publications published in journals in 2010-2012? This research aims to simulate several clusters of these graduate programs using cluster analysis. Therefore, simulations were made using five clustering methods with three distance measures on five variables proposed by Soares e Múrcia (2016). We conclude that depending on the distance measure used, the cluster layout of the graduate programs changes. In addition, we show that the nearest neighbors method generates clusters more difficult to be observed. Finally, we detected the recurrent association between some graduate programs as UFPR and Unisinos, and FURB and UFSC. Thus, the graduate programs in the south of Brazil have similar characteristics regarding publication. The USP stands out for isolating others graduate programs. Soares and Casa Nova (2015) 
have already shown to be indicative of these findings. This paper advances the discussion of the use of indicators of the bibliographic production for the evaluation of the quality of graduate programs. It is the argument of the authors of this paper that the System follows a rationality focused on product indicators, and that can deviate teachers and students from the concentration of efforts in the research process.

Keywords: Graduate programs. Accounting. Publications.

\section{CONSIDERAÇÕES INICIAIS}

Uma das funções basilares da pós-graduação, em sentido amplo, é a produção e disseminação de novos conhecimentos pelos docentes e discentes, por meio do desenvolvimento da pesquisa científica e disseminação do conhecimento gerado. A produção de conhecimento ocorre de diversas formas e engloba os textos produzidos em disciplinas, assim como as dissertações e teses desenvolvidas pelos estudantes, além dos trabalhos e artigos derivados dos projetos de pesquisa tanto dos docentes quanto dos discentes. A disseminação do conhecimento acontece, principalmente, pela exposição dos relatos de pesquisa em aulas e seminários na pós-graduação; em apresentações em eventos científicos, como congressos e encontros; e pela disponibilização dos artigos, após processo de avaliação pelos pares, em periódicos científicos. A construção do conhecimento, igualmente, ocorre pela construção de parcerias em pesquisa por meio da colaboração acadêmica interinstitucional.

Durante a vigência do triênio 2010-2012, para a Coordenação de Aperfeiçoamento de Pessoal de Nível Superior (Capes), os programas de pós-graduação stricto sensu se dividiam entre programas acadêmicos (mestrado e doutorado) e programas profissionais. Nas áreas de Administração, Ciências Contábeis e Turismo havia, à época, 17 programas de pós-graduação stricto sensu em Contabilidade e Controladoria. Esses programas, juntos, produziram 68 teses, 683 dissertações e publicaram mais de dois mil artigos em periódicos, três mil artigos em anais de eventos, 100 livros e 300 capítulos de livros (COORDENAÇÃO DE APERFEIÇOAMENTO DE PESSOAL DE NÍVEL SUPERIOR, 2013).

Com o intuito de compreender o estabelecimento de parcerias, uma série de pesquisas tem utilizado as coautorias, estabelecidas por meio do material bibliográfico criado no âmbito da pós-graduação em Contabilidade, para identificar as relações entre os pesquisadores e os programas de pós-graduação sob a perspectiva de redes sociais, como se observa em Souza et al. (2008), Espejo et al. (2009), Nascimento 
e Beuren (2011), Oliveira Neto e Meli (2011) e Silva et al. (2012), com o apoio do software Ucinet.

Diante desse contexto e das pesquisas anteriores, apresenta-se a seguinte questão de pesquisa: como se agrupam os programas de pós-graduação em Contabilidade, de acordo com as características das publicações veiculadas em periódicos, no período de 2010 a 2012? As características da produção bibliográfica, utilizadas para o agrupamento dos programas, são: pontuação total por programa de pós-graduação; pontuação média por professor; coeficiente de variação da produção; percentual de professores produtivos; e nível de inserção internacional.

Nesse sentido, objetiva-se, com esta pesquisa, compreender o agrupamento dos programas de pós-graduação, segundo a semelhança entre as características relativas às produções científicas. A produção científica dos programas tem tido peso relevante na avaliação da qualidade dos programas, feita pela Coordenação de Aperfeiçoamento de Pessoal de Nível Superior (Capes). Dessa forma, é importante entender a racionalidade por trás desse processo avaliativo. Para atingir esse objetivo, vários tipos de agrupamentos foram realizados, usando a análise de cluster.

A pesquisa de Souza et al. (2008) utilizou a análise de cluster concomitante com a análise de redes sociais para analisar os agrupamentos dos programas de pós-graduação em Contabilidade. Por sua vez, a pesquisa de Soares e Casa Nova (2015) utilizou a técnica de análise de cluster para agrupar os diversos programas acadêmicos de pós-graduação stricto sensu das áreas de Administração, Ciências Contábeis e Turismo, no triênio 2010-2012, com base no impacto de suas publicações, de acordo com o Google Scholar ${ }^{\circledR}$.

A justificativa desta pesquisa reside na continuidade longitudinal das análises acerca da produção bibliográfica dos programas de pós-graduação precedentes, ao estender a análise para a produção publicada durante o triênio 2010-2012 e, também, por se utilizar da análise de cluster como método quantitativo de análise, utilizado até então apenas na pesquisa de Souza et al. (2008). No entanto, diferente desses autores, que utilizaram apenas o método de agrupamento Ward e não especificaram a medida de distância escolhida, na presente pesquisa realizou-se a combinação entre diferentes métodos de agrupamento com diferentes medidas de distância, com o propósito de verificar as diferentes configurações de agrupamento, eliminando possíveis vieses decorrentes da escolha arbitrária desses critérios.

O resultado deste estudo é relevante tanto para a Capes quanto para os próprios programas de pós-graduação em Contabilidade, os docentes, discentes e coordenadores. Representantes da Capes e dos programas de pós-graduação podem ana- 
lisar as características dos programas com maior produtividade para elaborar novos parâmetros e critérios de produção. Podem, igualmente, servir de referência para os programas menos produtivos, para que firmem alianças com os programas mais produtivos, como é perceptível entre os programas da UFPR, Unisinos, FURB e UFSC. Assim, podem, como membros de uma comunidade de pesquisa, melhorar, uniformemente, a qualidade e a quantidade das produções na área Contábil.

Quanto à sua estrutura, o presente artigo se divide em cinco seções: esta introdução, na qual se apresentam a questão de pesquisa, os objetivos e a justificativa; a revisão de literatura, em que se examina a literatura acerca da evolução, avaliação e produção dos programas de pós-graduação em Contabilidade; a metodologia, que apresenta a população e a amostra, os dados e as escolhas metodológicas dos pesquisadores; a análise dos resultados, que discute os diversos agrupamentos, resultantes das análises de cluster; e, por fim, a conclusão, com os achados da pesquisa, sintetizados e discutidos, e a apresentação de sugestões para trabalhos futuros e de implicações para a área.

\section{REVISÃO DA LITERATURA}

\subsection{A EVOLUÇÃO DOS CURSOS DE PÓS-GRADUAÇÃO EM CONTABILIDADE NO BRASIL}

A constante necessidade de aperfeiçoar as técnicas, a progressiva busca pelo acúmulo de conhecimentos e a conveniência de formar especialistas e pesquisadores nas diversas áreas do conhecimento fez com que as autoridades brasileiras atentassem para a necessidade de implantar cursos de pós-graduação. Nesse sentido, mediante pronunciamento do Parecer n. 977, de 03 de dezembro de 1965, o extinto Conselho Federal de Educação (CFE) proferiu que os conhecimentos fornecidos em nível de graduação seriam considerados básicos (CONSELHO FEDERAL DE EDUCAÇÃO, 1965).

Destarte, de acordo com o mesmo Parecer, a pós-graduação no Brasil passou a ser implantada em "consequência natural do extraordinário progresso do saber em todos os setores, tornando impossível proporcionar treinamento completo e adequado para muitas carreiras nos limites dos cursos de graduação.” (CONSELHO FEDERAL DE EDUCAÇÃO, 1965).

A discussão formal sobre a pós-graduação no Brasil iniciou com a promulgação da Lei n. 4.024, de 20 de dezembro de 1961. Em relação à educação superior, 
a referida Lei relacionou, em seu art. 69 do capítulo I, os cursos que poderiam ser ministrados nas instituições de ensino superior. O primeiro item desse artigo tratou dos cursos de pós-graduação, que poderiam abrir matrícula a candidatos que tivessem concluído o curso de graduação e obtido o diploma referente à sua formação (BRASIL, 1961).

A atual legislação brasileira, responsável por regular a pós-graduação, esclarece que um programa de pós-graduação pode se constituir de diversos cursos, que se classificam, por sua vez, em duas distintas modalidades, lato sensu e stricto sensu, agrupadas de acordo com as suas características específicas.

A modalidade lato sensu compreende os cursos voltados para Especialização e Master of Business Administration (MBA), devendo, de acordo com Ministério da Educação (MEC), fornecer, no mínimo, 360 horas de educação, com o intuito de capacitar o profissional para a atuação prática-profissional. Na modalidade stricto sensu são ofertados cursos de Mestrado Profissional, Mestrado e Doutorado Acadêmico, tendo o primeiro um enfoque voltado ao desenvolvimento de competências profissionais e os dois últimos voltados à formação de professores universitários e pesquisadores, respectivamente.

A implantação dos primeiros programas stricto sensu em Contabilidade, no Brasil, ocorreu nos anos 1970. O pioneiro foi o Programa de Mestrado da Faculdade de Economia, Administração e Contabilidade da Universidade de São Paulo (FEA-USP), em 1970. Na mesma década foi criado o Programa de Mestrado em Ciências Contábeis e Atuariais da Pontifícia Universidade Católica de São Paulo (PUC-SP), que iniciou suas atividades no ano 1978.

Em 1978 também foi instituído o primeiro Programa de Doutorado em Ciências Contábeis na FEA-USP, o qual vem influenciando, de maneira decisiva, a pesquisa contábil brasileira, ao passo que a maioria absoluta dos doutores em Ciências Contábeis brasileiros é composta por egressos desse Programa (PELEIAS et al., 2007).

Os programas de pós-graduação stricto sensu em Ciências Contábeis concentraram-se na região Sudeste por algumas décadas, sendo necessário deslocarem-se de outras regiões os profissionais que almejavam obter o título de mestre ou doutor na área. Peleias et al. (2007, p. 27) declaram que a implantação de novos programas stricto sensu em Contabilidade voltou a ocorrer na década de 1990 e no início do século XXI, evidenciando, em seu estudo, os motivos responsáveis pela oferta dos novos programas: 
Exigências da Lei 9394/96, nos itens II e III do art. 52, para que pelo menos um terço do corpo docente das instituições de ensino superior, a partir de Centro Universitário, fosse de professores com titulação mínima de Mestrado e da existência de professores em tempo integral, dedicados à docência e à pesquisa; o aumento na oferta de cursos superiores no Brasil, e dentre esses os de Ciências Contábeis, ocorrida ao longo da década de 1990; o aumento no número de professores doutores em Ciências Contábeis ocorrido no período, apesar de o Brasil ainda possuir, à época, apenas um programa de Doutorado na área; a atuação de professores doutores em outras áreas que não em Ciências Contábeis nos programas Stricto Sensu em Contabilidade, o que, em parte, reduziu a restrição de haver apenas um Doutorado na área no País e contribuiu para minimizar a endogenia do corpo docente desses Programas.

A multiplicação dos programas de mestrado em Contabilidade ocorreu, principalmente, a partir da primeira década do século XXI (SOARES; PFITSCHER, 2012). Já para os programas de doutorado em Contabilidade isso ocorreu a partir do ano 2012.

A Capes é o órgão responsável por avaliar os programas de pós-graduação brasileiros, bem como por credenciar os cursos que buscam a sua recomendação. Conhecer os mecanismos de avaliação desse órgão torna-se relevante, pois, a partir desse conhecimento, pode-se compreender como os programas de pós-graduação em Contabilidade estão qualificados e, assim, discutir outras alternativas de avaliação, que tragam impactos positivos para a formação e a qualificação de docentes e pesquisadores.

\subsection{A CAPES E OS CRITÉRIOS DE AVALIAÇÃO DOS PROGRAMAS DE PÓS-GRADUAÇÃO E PERIÓDICOS}

A Capes foi criada em 11 de julho de 1951, por meio do Decreto n. 29.741, com o objetivo de "assegurar a existência de pessoal especializado em quantidade e qualidade suficientes para atender às necessidades dos empreendimentos públicos e privados que visam o desenvolvimento do país.” (BRASIL, 1951).

No âmbito da educação superior, sabe-se, de acordo com a legislação vigente, que a Capes é um órgão vinculado ao MEC, com a responsabilidade de normatizar e avaliar a pós-graduação no País. Destacam-se, entretanto, outras quatro grandes fun- 
ções desse órgão, desenvolvidas como programas: acesso e divulgação da produção científica; investimentos na formação de recursos de alto nível no País e no exterior; produção da cooperação científica internacional; e indução e fomento da formação inicial e continuada de professores para a educação básica, nos formatos presencial e a distância (COORDENAÇÃO DE APERFEIÇOAMENTO DE PESSOAL DE NÍVEL SUPERIOR, 2012).

Para avaliar a pós-graduação stricto sensu, a Capes utiliza um sistema de avaliação que vem sendo continuamente aperfeiçoado, com o intuito de servir de instrumento para a comunidade universitária, na busca de um padrão de excelência acadêmica para os cursos de mestrado e doutorado nacionais (MURCIA; ROSA; BORBA, 2013). Sobre a avaliação dos cursos de educação superior, Peleias (2006) considera que todo projeto é preparado no sentido de ser executado e de gerar bons frutos. Contudo, deve haver um processo avaliativo, considerado fundamental para atestar o funcionamento, identificar a necessidade de correções e levantar considerações acerca desse plano.

O sistema de avaliação compõe-se de observações tanto da avaliação dos programas de pós-graduação quanto das propostas de novos cursos de pós-graduação. Quanto à avaliação dos programas de pós-graduação, realizam-se o acompanhamento anual e a avaliação trienal do desempenho de todos os cursos e programas que constituem o Sistema Nacional de Pós-Graduação (SNPG). A mais recente avaliação trienal de desempenho foi realizada no triênio 2010-2012, atribuindo conceitos aos programas, de acordo com a sua performance acadêmica. Após esse período, a avaliação se tornou quadrienal.

As notas utilizadas para mensurar o desempenho dos programas de pós-graduação variam conforme o cumprimento de pré-requisitos estabelecidos pela Capes. Os programas podem obter notas que variam em uma escala de 1 a 7. Diversos pré-requisitos são observados, cada um com pesos específicos, em cada um dos cinco itens avaliados de cada programa (quesitos): Proposta do Programa; Corpo Docente; Corpo Discente, Teses e Dissertações; Produção Intelectual; e Inserção Social. Os quesitos possuem pesos correspondentes a 0\%, 20\%, 35\%, 35\% e 10\%, respectivamente. A Proposta do Programa não possui peso, pois passa por uma avaliação qualitativa referente à coerência, histórico e planos de futuro.

Há alguns estudos que constituem a criação de sistemas paralelos de avaliação de programas, independentes da Capes, ou fundamentam críticas que visam ao seu aprimoramento, como se observa em Igarashi et al. (2008) e Lins, Almeida e Bartholo Junior (2004). Quanto à avaliação da produção científica dos programas de 
pós-graduação, a Diretoria de Avaliação da Capes desenvolveu um sistema de avaliação da qualidade dos periódicos para fins de avaliação da produção bibliográfica dos programas, denominado Qualis Periódicos, o qual é criticado em diversos estudos (ROCHA-E-SILVA, 2009; SOARES; CASA NOVA, 2016).

O Qualis é descrito pela própria Capes como o conjunto de procedimentos utilizado para estratificar a qualidade da produção intelectual dos programas de pós-graduação. Informações do website da Capes ainda esclarecem que “a estratificação da qualidade dessa produção é realizada de forma indireta” pela aferição “da qualidade dos artigos e outros tipos de produção, a partir da análise da qualidade dos veículos de divulgação, ou seja, periódicos científicos.” (COORDENAÇÃO DE APERFEIÇOAMENTO DE PESSOAL DE NÍVEL SUPERIOR, 2014).

A título de complementação, detalham-se algumas características dessa classificação: a classificação de periódicos é realizada pelas áreas de avaliação e passa por processo anual de atualização. Esses veículos, os periódicos acadêmicos, são enquadrados em estratos indicativos de qualidade, sendo A1 o estrato mais elevado, seguido pelos demais, que são A2, B1, B3, B4, B5, C. Cada estrato tem uma pontuação específica que vai de 100 (estrato A1) até zero (estrato C) (COORDENAÇÃO DE APERFEIÇOAMENTO DE PESSOAL DE NÍVEL SUPERIOR, 2014). De acordo com essa tabela de correspondência, cada docente e discente pode ser avaliado em termos de pontos para um período de tempo, triênio ou quadriênio, que que são somados para se obter a pontuação do programa.

O sistema de avalição da pós-graduação, implantado pela Capes, desenvolve um papel de fundamental importância para o desenvolvimento da pós-graduação e da pesquisa científica e tecnológica no Brasil. O resultado das avaliações fornece respaldo para a base de formulação de políticas para a área da pós-graduação, bem como para o direcionamento de ações dos órgãos de fomento. As estatísticas e informações geradas permitem, ainda, a realização de estudos e pesquisas, que se consolidam em análises críticas da produção, dos programas, da formação e do próprio sistema.

A seguir, no próximo tópico, serão tratados alguns dos estudos referidos nesta seção. 


\subsection{PESQUISAS QUE ANALISAM OS PROGRAMAS DE PÓS- GRADUAÇÃO EM CONTABILIDADE, SEGUNDO A PRODUÇÃO BIBLIOGRÁFICA}

Diversas pesquisas analisaram a produção bibliográfica dos programas de pós-graduação, destacando-se, entre elas, os estudos realizados por Souza et al. (2008), Espejo et al. (2009), Nascimento e Beuren (2011), Oliveira Neto e Meli (2011), Silva et al. (2012), Soares, Richartz e Múrcia (2013) e Soares e Múrcia (2016). Atendo-se somente às publicações mais recentes, torna-se possível destacar alguns resultados interessantes, referentes aos padrões das produções bibliográficas, observadas nesses estudos.

Souza et al. (2008) pesquisaram a composição das redes de colaboração entre programas de pós-graduação. Utilizando dados da produção bibliográfica, veiculada em eventos científicos, nos anos 2006 e 2007, as autoras identificaram que a USP, a Fucape, a UFSC e a UnB ocupavam a centralidade da rede de coautorias, enquanto as demais instituições ocupavam a zona periférica.

Espejo et al. (2009) realizaram pesquisa similar à de Souza et al. (2008), analisando indicadores bibliométricos e sociométricos acerca da produção bibliográfica, veiculada em anais de eventos e periódicos científicos, entre os anos 2004 e 2008. A USP, como Instituição, ocupou a centralidade da rede em razão do fato de possuir o maior número de vínculos com os autores mapeados. A UnB e a UFPE são a segunda e a terceira instituições com mais vínculos de autoria, respectivamente. O resultado converge, em parte, com a pesquisa de Souza et al. (2008). A diferença pode ser explicada pelo fato de que Espejo et al. (2009) incluíram artigos de periódicos em sua análise, o que não foi feito na pesquisa de Souza et al. (2008), que consideraram apenas a produção em eventos científicos.

Nascimento e Beuren (2011) fizeram uma análise das publicações sob a ótica das redes sociais de pesquisa, no triênio 2007-2009. Os resultados da pesquisa mostraram que a produção científica definitiva, veiculada em periódicos, pelos docentes permanentes dos programas analisados, apresentava-se dispersa nas estratificações do Qualis-Capes, e que a centralidade da rede social era ocupada pelo programa da USP, seguida pelos programas da UPM, USP-RP, UFMG, Fucape, Unifecap e FURB. O estudo demonstrou, ainda, que os programas de pós-graduação em ciências contábeis apresentavam ligações fracas, esparsas e pouco densas.

Oliveira Neto e Meli (2011) analisaram a composição da rede de colaboração em pesquisa, segundo os artigos publicados em sete periódicos de contabilidade 
brasileiros. Os autores concluíram que a rede era fragmentada, sendo composta, em grande parte, por autores que publicaram um único artigo. Diferente das pesquisas anteriormente relacionadas, Oliveira Neto e Meli (2011) limitaram-se a analisar a composição da rede de colaboração entre os autores, não abrangendo, assim, a análise da rede de colaboração entre instituições.

Silva et al. (2012) também analisaram a produção dos docentes dos programas de pós-graduação em Contabilidade, referente ao triênio 2007-2009, sob a perspectiva de redes de colaboração científica, e concluíram que os programas da USP e da FURB ocupavam a centralidade das redes e que os programas da Fucape, FURB, PUC-SP, UFBA, UFPE, UFRJ, UFSC e Unisinos apresentavam uma evolução dos vínculos das redes de colaboração.

A pesquisa desenvolvida por Soares, Richartz e Múrcia (2013) analisou os programas de pós-graduação brasileiros stricto sensu, acadêmicos e profissionais, durante o triênio de 2007-2009, considerando cinco indicadores: pontuação total por programa de pós-graduação; pontuação média por professor; coeficiente de variação da produção; percentual de professores produtivos; e nível de inserção internacional. Os autores concluíram que as instituições que tiveram melhor desempenho foram USP, FURB, Fucape, USP-RP e UFPE.

Por último, Soares e Múrcia (2016), em sua pesquisa, analisaram os programas de pós-graduação brasileiros stricto sensu, mas, diferente de Soares, Richartz e Múrcia (2013), restringiram-se aos programas acadêmicos, durante o triênio 20102012, considerando os mesmos cinco indicadores, embora tenham feito alterações metodológicas em relação ao trabalho precedente. Os resultados apontaram que determinadas IES (como USP, FURB, UFSC, Fucape e UnB) apresentaram melhor desempenho que as demais, indo ao encontro dos achados na pesquisa de Soares, Richartz e Múrcia (2013).

Tais pesquisas, no entanto, apenas tangenciam o objetivo do presente estudo que, portanto, não é idêntico a nenhum dos estudos anteriores. Mesmo o estudo de Soares e Múrcia (2016), em cujos dados esta pesquisa se apoia para o desenvolvimento das análises, limita-se a avaliar o desempenho dos programas, segundo cinco critérios predeterminados para o estabelecimento de rankings com base em scores.

O objetivo com a presente pesquisa foi identificar quais programas têm produção bibliográfica semelhante, utilizando a técnica de análise de cluster. A partir dessa análise que se pretende, parcerias em pesquisa podem ser estruturadas entre programas semelhantes, e modelos de atuação podem ser identificados para que se estabeleçam ações. 
Isso posto, passa-se ao próximo tópico, no qual será descrita a metodologia adotada neste estudo.

\section{METODOLOGIA}

\subsection{POPULAÇÃO E AMOSTRA}

A população foco desta pesquisa é composta pelo total de programas de pós-graduação stricto sensu acadêmicos, que tiveram atuação em, pelo menos, um dos anos do triênio 2010-2012. A lista dos programas incluídos é apresentada no Quadro 1, que relaciona programa por instituição e por região do País:

Quadro 1 - Amostra da pesquisa

\begin{tabular}{|c|c|c|}
\hline Região & Instituição & Programa \\
\hline \multirow{4}{*}{ Nordeste } & UFBA & Contabilidade \\
\cline { 2 - 3 } & UFC & Administração e Controladoria \\
\cline { 2 - 3 } & UFPE & Ciências Contábeis \\
\cline { 2 - 3 } & UnB/UFPB/UFRN & Contabilidade - UnB - UFPB - UFRN \\
\hline \multirow{5}{*}{ Sudeste } & Fucape & Ciências Contábeis \\
\cline { 2 - 3 } & PUC-SP & Ciências Contábeis e Atuariais \\
\cline { 2 - 3 } & UERJ & Ciências Contábeis \\
\cline { 2 - 3 } & UFES & Ciências Contábeis \\
\cline { 2 - 3 } & UFMG & Ciências Contábeis \\
\cline { 2 - 3 } & UFRJ & Ciências Contábeis \\
\cline { 2 - 3 } & Unifecap & Ciências Contábeis \\
\cline { 2 - 3 } & USP & Controladoria e Contabilidade \\
\cline { 2 - 3 } & USP-RP & Controladoria e Contabilidade \\
\cline { 2 - 3 } & FURB & Ciências Contábeis \\
\hline \multirow{5}{*}{ Sul } & UFPR & Contabilidade \\
\cline { 2 - 3 } & UFSC & Contabilidade \\
\cline { 2 - 3 } & Unisinos & Ciências Contábeis \\
\cline { 2 - 3 } & &
\end{tabular}

Fonte: os autores.

Pela análise do Quadro 1, observa-se que havia quatro programas da região Sul, nove programas da região Sudeste e três programas na região Nordeste. Os programas stricto sensu da Fucape, Ufam, UFC e UPM não foram incluídos na amostra, dado que são programas stricto sensu profissionais, e, conforme Soares e Múrcia (2016), não é adequado comparar a produção bibliográfica de programas acadêmicos com programas profissionais. Assim, a região Norte não apresentou nenhum progra- 
ma analisado e a região Centro-Oeste apresentou apenas o da UnB. As variáveis analisadas e os dados utilizados tiveram origem no artigo de Soares e Múrcia (2016).

\subsection{DADOS UTILIZADOS}

Os dados utilizados são oriundos da pesquisa de Soares e Múrcia (2016), que analisaram os programas de pós-graduação em Contabilidade com base em cinco critérios: produção total do programa; nível de inserção internacional; produção média por professor; coeficiente de variação da produção; e percentual de professores produtivos.

No Quadro 2, a seguir, descrevem-se essas variáveis e a forma de coleta:

Quadro 2 - Variáveis utilizadas na pesquisa

\begin{tabular}{|c|c|}
\hline Coleta & Variável \\
\hline $\begin{array}{l}\text { Os dados dessa variável foram fornecidos pelos próprios progra- } \\
\text { mas, por meio do aplicativo Coleta Capes, para a avaliação trienal } \\
2010-2012 \text {. }\end{array}$ & $\begin{array}{l}\text { Pontuação total por programa de } \\
\text { pós-graduação }\end{array}$ \\
\hline $\begin{array}{l}\text { Os dados dessa variável foram coletados nos currículos lattes dos } \\
\text { professores. Para levantar os dados dessa variável, primeiro calcu- } \\
\text { lou-se a média de pontos da produção, por ano, de cada professor, } \\
\text { dividindo-se a soma das produções do docente pelo número de } \\
\text { períodos em que teve vínculo como docente permanente ou cola- } \\
\text { borador. Depois, calculou-se a média das médias dos docentes. Os } \\
\text { docentes que tiveram vínculo exclusivamente de visitante, durante } \\
\text { o período, não foram inseridos no cálculo, permitindo a compara- } \\
\text { bilidade matemática de docentes com períodos distintos de vínculo } \\
\text { ao programa. }\end{array}$ & Pontuação média por professor \\
\hline $\begin{array}{l}\text { O coeficiente de variação da produção foi calculado pela divisão } \\
\text { do desvio padrão da produção de todos os docentes, permanentes } \\
\text { ou colaboradores, excluídos os visitantes, pela média de pontos } \\
\text { por ano. }\end{array}$ & $\begin{array}{l}\text { Coeficiente de variação da pro- } \\
\text { dução }\end{array}$ \\
\hline $\begin{array}{l}\text { O percentual de docentes produtivos foi calculado pelo número de } \\
\text { docentes permanentes ou colaboradores com produção acima de } \\
50 \text { pontos por ano. }\end{array}$ & $\begin{array}{l}\text { Percentual de professores produ- } \\
\text { tivos }\end{array}$ \\
\hline $\begin{array}{l}\text { O nível de inserção internacional foi calculado pela soma dos pon- } \\
\text { tos de artigos de revistas localizados nos estratos A1 e A2, declara- } \\
\text { dos pelos programas no Coleta Capes. }\end{array}$ & Nível de inserção internacional \\
\hline
\end{tabular}

Fonte: adaptado de Soares e Múrcia (2016).

Como se pode ver, a maior parte dos dados foi coletada diretamente das fichas da avaliação trienal da Capes e em consulta aos currículos lattes dos docen- 
tes. Portanto, sobre os dados utilizados há uma margem associada de erro decorrente do preenchimento incorreto do Coleta Capes pelos programas; de erro decorrente do preenchimento incorreto ou desatualização do currículo lattes por parte dos docentes; e de erro decorrente do registro ou cômputo incorreto por parte de Soares e Múrcia (2016).

Há que se ressalvar que existe uma associação entre esses diversos indicadores, como se demonstra na Tabela 1 , a qual elenca os coeficientes de correlação linear $r$ de Pearson:

Tabela 1 - Matriz de correlação das variáveis da pesquisa

\begin{tabular}{l|r|r|r|r|r}
\hline \multicolumn{1}{c|}{ Variável } & $\begin{array}{c}\text { Produção } \\
\text { total }\end{array}$ & $\begin{array}{c}\text { Inserção in- } \\
\text { ternacional }\end{array}$ & $\begin{array}{c}\text { Prod. média } \\
\text { por prof. }\end{array}$ & $\begin{array}{c}\text { Coeficiente } \\
\text { de variação }\end{array}$ & $\begin{array}{c}\text { \% prof. } \\
\text { produtivos }\end{array}$ \\
\hline $\begin{array}{l}\text { Produção } \\
\text { total }\end{array}$ & 1 & & & & \\
\hline $\begin{array}{l}\text { Inserção } \\
\text { internacional }\end{array}$ & $0,686294^{* * *}$ & 1 & & & \\
\hline $\begin{array}{l}\text { Prod. média } \\
\text { por prof. }\end{array}$ & $0,643766^{* * *}$ & 0,343707 & & & \\
\hline $\begin{array}{l}\text { Coeficiente de } \\
\text { variação }\end{array}$ & $-0,46526^{*}$ & $-0,47496^{*}$ & 0,014594 & & 1 \\
\hline $\begin{array}{l}\% \text { prof. pro- } \\
\text { dutivos }\end{array}$ & $0,670405^{* * *}$ & $0,547428^{* *}$ & $0,627083^{* * *}$ & $-0,42844^{*}$ & \\
\hline
\end{tabular}

Considerando que todas as variáveis constituem métricas acerca de diferentes facetas da produção bibliográfica, é natural que diversas correlações tenham se mostrado estatisticamente significativas. A produção total, por exemplo, está correlacionada com a produção média por professor, pois é resultado da soma da produção de todos os docentes, sem duplicidades. A correlação entre produção total e inserção internacional também é esperada, pois, teoricamente, espera-se que programas que produzem mais também publiquem mais internacionalmente. Isso também vale para a correlação entre a produtividade média por professor e o \% de professores produtivos, porque, teoricamente, espera-se que a produção esteja distribuída entre os docentes e que não haja concentrações anormais.

Embora nenhuma correlação possa ser considerada forte, há correlações que podem até ser consideradas moderadas, ou seja, aquelas que se aproximam de 0,7. As análises foram realizadas nos softwares Stata 14 e SPSS 20. 


\subsection{ANÁLISE DE CLUSTER}

A análise de cluster é uma ferramenta de análise multivariada, bastante popular na área de pesquisa em Administração e Contabilidade, abordada por diversos autores, como em Mingoti (2005), Oliveira (2007), Manly (2008), Corrar, Paulo e Dias Filho (2009), Fávero et al. (2009), Hair Junior et al. (2009), Lattin, Carroll e Green (2011), Malhotra (2012), Ribas e Vieira (2011), Loesch e Hoeltgebaum (2012) e Fávero e Belfiore (2015, 2017).

Para Fávero et al. (2009, p. 196) a análise de cluster "é uma técnica estatística de interdependência, que permite agrupar casos ou variáveis em grupos homogêneos em função do grau de similaridade entre os indivíduos, a partir de variáveis predeterminadas.” Hair Junior et al. (2009, p. 430) afirmam que a “análise de agrupamentos é um grupo de técnicas multivariadas cuja finalidade principal é agregar objetos com base nas características que eles possuem.”

Fávero et al. (2009) alertam que é recomendável verificar a existência de outliers antes de efetuar a análise de cluster, mas que é comum que indivíduos atípicos formem grupos isolados e que isso pode ser exatamente o que o pesquisador está procurando, de forma que cabe a este remover ou não a observação.

Segundo Sicsú (2004), a classificação das técnicas ou dos métodos de agrupamento ocorre entre partição, hierárquicas e cobertura. Como se pretende obter agrupamentos com nível distinto de desempenho, optou-se, neste estudo, pelo agrupamento hierárquico, em que há superposição na obtenção dos agrupamentos, mas não há superposição entre os agrupamentos resultantes.

Os agrupamentos podem ser obtidos por técnicas aglomerativas ou Ward. No primeiro caso, tem-se o centroide e a ligação entre os objetos. Essas técnicas se diferenciam pela forma de medir a distância entre os objetos. A técnica Ward, por sua vez, tem por base a variância interna dos grupos. Sicsú (2004) ainda ressalta que técnicas diferentes conduzem a resultados diversos, sendo que não é possível determinar qual seja a técnica superior. E prossegue observando que se deve simular modelos com a utilização de diferentes técnicas e comparar os resultados, buscando entender o porquê das inconsistências.

Como as diferenças de escalas das variáveis podem distorcer a estrutura do agrupamento, costuma-se, por isso, padronizar as variáveis, sendo a mais comum a padronização $Z$, que é dada pela fórmula: 


$$
Z=\frac{(x-\text { média })}{\text { desvio padrão }} Z=\frac{(x-\text { média })}{\text { desvio padrão }}
$$

Em que $Z Z$ é o valor padronizado e $x x$ é a observação.

Após proceder a padronização, a presença de outliers foi analisada por meio do diagrama de caixa.

Não houve nenhum valor discrepante na variável percentual de professores produtivos. No entanto, houve valores discrepantes nas quatro variáveis restantes, sendo que: os programas da FURB e da UFSC apresentaram valores discrepantes na variável pontuação média por professor; o programa da USP apresentou valor discrepante na variável inserção internacional; o programa da FURB apresentou valor discrepante na variável pontuação total; e o programa da UERJ apresentou valor discrepante na variável coeficiente de variação, enquanto que, na mesma variável, os programas da PUC-SP e UFES apresentaram valores discrepantes. Todavia, dado que a exclusão dos valores discrepantes implicaria a eliminação de 6 dos 17 programas da amostra, e que muitos desses valores se devem à atuação efetiva do programa naquela dimensão, não sendo derivados de erro, optou-se por manter todos na análise.

\subsection{ESCOLHAS METODOLÓGICAS}

No decorrer da pesquisa foram realizadas algumas escolhas metodológicas que merecem esclarecimento. A primeira delas tratou de limitar a amostra aos programas de pós-graduação stricto sensu acadêmicos, excluindo os profissionais. A razão é que a pesquisa de Soares e Múrcia (2016) já havia feito essa eliminação por considerar inadequada a comparação de programas acadêmicos com programas profissionais. A justificativa dos autores é que os programas stricto sensu profissionais não têm o mesmo foco em produção de conhecimento que os acadêmicos, de modo que a comparação da produção bibliográfica dos programas tende a favorecer os acadêmicos.

A segunda escolha foi o uso da análise de cluster para analisar os dados. A justificativa para a escolha dessa técnica se apoia no trabalho de Soares e Casa Nova (2015). Os autores utilizaram essa mesma técnica nos programas de pós-graduação acadêmicos das áreas de Administração, Ciências Contábeis e Turismo. No entanto, optaram por usar o método não hierárquico $k$-means, pois tinham por objetivo agrupar os programas em cinco estratos, em uma analogia aos cinco conceitos com os quais os 
programas reconhecidos pela Capes são avaliados, ou seja, a atribuição de conceitos entre 3 e 7.

Nesta pesquisa optou-se por simular os agrupamentos, usando diversos algoritmos com diferentes medidas de distância.

\section{ANÁLISE DOS RESULTADOS}

\subsection{ANÁLISE DESCRITIVA DOS INDICADORES}

Inicialmente, são apresentados os dados originais, com uma análise estatística descritiva, conforme se expõe na Tabela 2:

Tabela 2 - Indicadores de análise dos programas com estatísticas descritivas

\begin{tabular}{|c|c|c|c|c|c|}
\hline Programa & $\begin{array}{r}\text { Pontuação } \\
\text { total }\end{array}$ & $\begin{array}{l}\text { Inserção in- } \\
\text { ternacional }\end{array}$ & $\begin{array}{l}\text { Média por } \\
\text { professor }\end{array}$ & $\begin{array}{r}\text { Coef. varia- } \\
\text { ção }\end{array}$ & $\begin{array}{c}\text { Percentual } \\
\text { professores } \\
\text { produtivos }\end{array}$ \\
\hline Fucape & 5400 & 3260 & 212.95 & 0.47 & $92 \%$ \\
\hline FURB & 15590 & 1780 & 371.37 & 0.75 & $100 \%$ \\
\hline PUC-SP & 1390 & 560 & 30.28 & 1.52 & $75 \%$ \\
\hline UERJ & 2830 & 320 & 51.48 & 1.29 & $33 \%$ \\
\hline UFBA & 2530 & 260 & 75.00 & 0.83 & $50 \%$ \\
\hline UFC & 5080 & 760 & 132.22 & 0.9 & $56 \%$ \\
\hline UFES & 3860 & 820 & 355.71 & 1.76 & $71 \%$ \\
\hline UFMG & 5390 & 1860 & 140.61 & 0.71 & $82 \%$ \\
\hline UFPE & 2840 & 320 & 87.31 & 0.74 & $69 \%$ \\
\hline UFPR & 7740 & 960 & 190.00 & 0.82 & $82 \%$ \\
\hline UFRJ & 4500 & 860 & 73.75 & 0.58 & $67 \%$ \\
\hline UFSC & 12120 & 2580 & 379.17 & 0.82 & $100 \%$ \\
\hline UnB & 10330 & 1180 & 166.11 & 0.53 & $95 \%$ \\
\hline Unifecap & 1570 & 400 & 63.94 & 1.08 & $45 \%$ \\
\hline Unisinos & 5450 & 820 & 191.67 & 0.84 & $92 \%$ \\
\hline USP & 14310 & 5220 & 139.39 & 0.54 & $86 \%$ \\
\hline USP-RP & 2270 & 960 & 95.15 & 0.86 & $82 \%$ \\
\hline Média & 6070 & 1348 & 162.12 & 0.88 & $75 \%$ \\
\hline Máximo & 15590 & 5220 & 379.17 & 1.76 & $100 \%$ \\
\hline Mediana & 5080 & 860 & 139.39 & 0.82 & $82 \%$ \\
\hline Mínimo & 1390 & 260 & 30.28 & 0.47 & $33 \%$ \\
\hline Análise & $\begin{array}{r}\text { Quanto } \\
\text { maior, me- } \\
\text { lhor }\end{array}$ & $\begin{array}{l}\text { Quanto } \\
\text { maior, me- } \\
\text { lhor }\end{array}$ & $\begin{array}{r}\text { Quanto maior, } \\
\text { melhor }\end{array}$ & $\begin{array}{l}\text { Quanto me- } \\
\text { nor, melhor }\end{array}$ & $\begin{array}{r}\text { Quanto maior, } \\
\text { melhor }\end{array}$ \\
\hline
\end{tabular}

Na última linha da tabela sinaliza-se a interpretação dos indicadores. Chama-se a atenção para o fato de que os três primeiros indicadores são interpretados, 
de forma simplista, “quanto maiores, melhores”. Para o quarto indicador, coeficiente de variação, a interpretação inverte-se: quanto menor, melhor. O último indicador, percentual de professores produtivos, segue a lógica dos três primeiros indicadores, portanto, quanto maior, melhor.

Tem-se, ainda, pela análise das informações da tabela, que os programas com melhores indicadores para a pontuação total, inserção internacional, média por professor, coeficiente de variação e percentual de professores produtivos são, respectivamente: FURB, USP, UFSC e UnB; USP, Fucape, UFSC e UFMG, seguidos de perto pela FURB; UFSC, FURB, UFES e Fucape; Fucape, UnB, USP e UFRJ; FURB, UFSC, UnB, Fucape e Unisinos.

Conclui-se que, considerando esses indicadores, os programas com desempenho destacado em mais de um deles são: FURB (em quatro dos cinco indicadores); UFSC (em quatro dos cinco indicadores); Fucape (em quatro dos cinco indicadores); USP (em três dos cinco indicadores); UnB (em três dos cinco indicadores); Unisinos e UFRJ (em um dos cinco indicadores). Ressalte-se que todas essas instituições ofertam programa de mestrado e de doutorado, sendo USP, FURB e UnB as que mantêm o doutorado há mais tempo. Pela racionalidade de agrupamento da análise de clusters, espera-se que esses programas se agrupem entre si e se distanciem dos demais.

\subsection{SIMULAÇÕES DE AGRUPAMENTOS COM BASE EM ANÁLISE DE CLUSTERS}

Seguindo a indicação de Sicsú (2004), as simulações foram efetuadas usando o mesmo método de agrupamento (hierárquico) e diversos métodos de cálculos de distância. Foram realizadas combinações com cinco métodos de agrupamento e três medidas de distância. Os métodos de agrupamento utilizados foram: ligação entre grupos, vizinho mais próximo, vizinho mais distante, armazenamento em cluster centroide e método Ward. As medidas de distância utilizadas foram: distância quadrática euclidiana, Chebychev e Manhattan.

A medida de distância euclidiana, embora seja muito comum em pesquisa em Administração (OLIVEIRA, 2007; FÁVERO et al., 2009), não foi utilizada nesta pesquisa por dois motivos. O primeiro deles é que os agrupamentos pela ligação entre grupos, vizinho mais próximo e vizinho mais distante, com a distância euclidiana e a distância quadrática euclidiana são os mesmos. O segundo é que o SPSS e o STATA, em seus manuais de comandos, recomendam o uso da distância quadrática euclidiana para os métodos de agrupamentos centroide e Ward. Com o objetivo de uniformizar 
a apresentação dos dendrogramas entre os cinco métodos, optou-se por apresentar apenas aqueles resultantes do uso da distância quadrática euclidiana.

Ressalta-se, ainda, que a medida de distância Minkowski foi utilizada indiretamente, por ser uma medida de distância genérica, dada em função de p, de forma que, quando $\mathrm{p}=1$, tem-se a medida Manhattan; e quando $\mathrm{p}=2$, tem-se a medida quadrática euclidiana (LATTIN; CARROLL; GREEN, 2011).

O primeiro método utilizado foi a ligação entre grupos ou average linkage, no qual os dendrogramas foram criados por meio das três medidas de distância anteriormente citadas. $\mathrm{O}$ primeiro dendrograma se refere à distância quadrática euclidiana, conforme se demonstra a seguir, no Gráfico 1:

Gráfico 1 - Dendrograma resultante do método ligação entre grupos e distância quadrática euclidiana

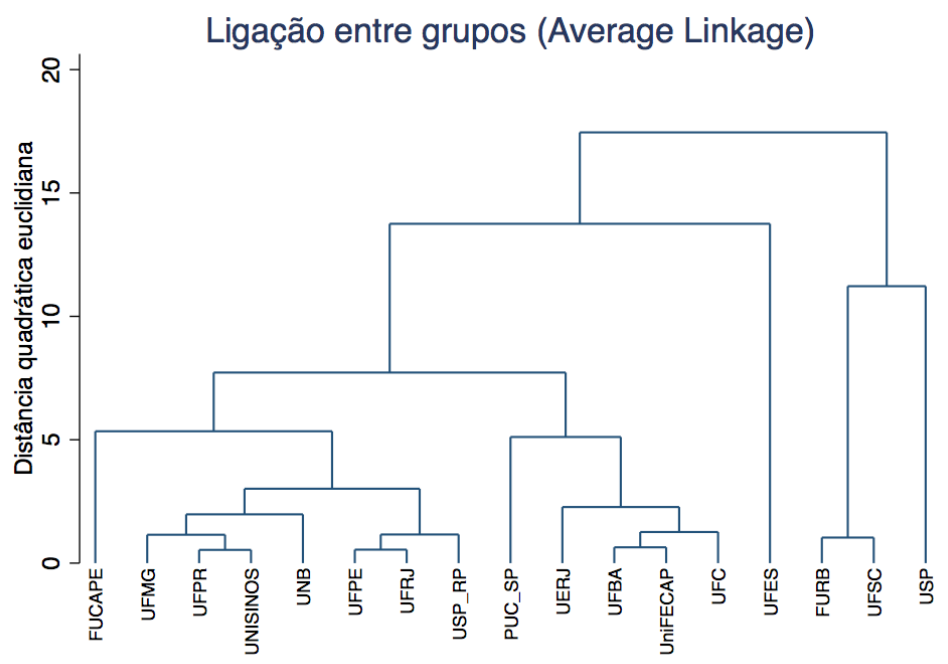

Fonte: os autores.

Nota-se que o método de ligação entre grupos com a medida de distância quadrática euclidiana forma clusters bem-definidos. Por exemplo, se se traçar uma linha um pouco acima do ponto 5, são formados cinco clusters, no qual os programas da UFES e da USP não se ligam a nenhum dos outros programas. Os outros clusters formados são: Fucape, UFMG, UFPR, Unisinos, UnB, UFPE, UFRJ e USP-RP; PUC-SP, UERJ, UFBA, Unifecap e UFC; e FURB e UFSC. O cluster formado pela USP, UFSC e FURB era esperado: as três instituições apresentaram um alto desempenho na pesquisa de Soares e Múrcia (2016), ocupando posições no topo do desempenho em quase todos os critérios. 
O segundo dendrograma (Gráfico 2) demonstra o método ligação entre grupos e a medida de distância Chebychev:

Gráfico 2 - Dendrograma resultante do método ligação entre grupos e distância Chebychev

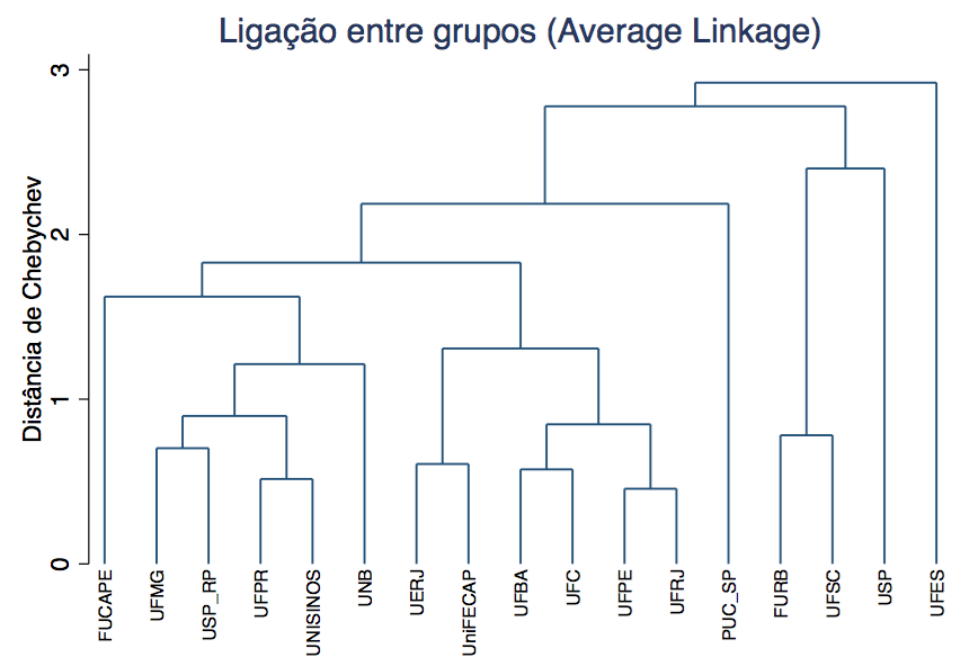

Fonte: os autores.

Assim como a distância quadrática euclidiana, o método de ligação entre grupos por meio da distância Chebychev apresenta clusters de fácil observação. Caso seja traçada uma linha embaixo do ponto 2, há a formação de seis clusters, em que tanto os programas da USP e da UFES se mantêm isolados tanto o da PUC-SP. Os outros clusters formados são: Fucape, UFMG, USP-RP e UFPR, Unisinos, UnB; UERJ, Unifecap, UFBA, UFC, UFPE e UFRJ; e FURB e UFSC. O distanciamento da UnB, da USP e da Fucape diverge do encontrado nas pesquisas anteriores, como as de Souza et al. (2008) e Espejo et al. (2009), denotando que as características de sua produção bibliográfica estão migrando para próximo das demais instituições.

O último dendrograma (Gráfico 3) do método ligação entre grupos é o da medida de distância Manhattan: 


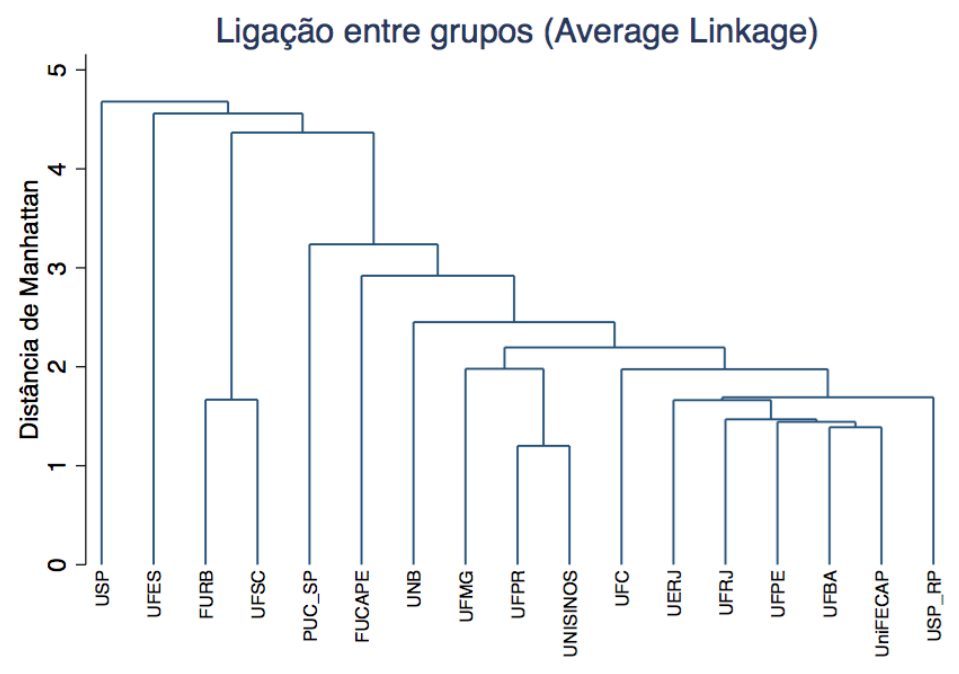

Fonte: os autores.

Diferente das outras distâncias, a formação dos clusters é mais difícil de ser observada. Contudo, se se traçar uma linha no ponto 2, observa-se a existência de oito clusters, dos quais os programas da USP, UFES, PUC-SP, Fucape e UnB não se agregaram, primariamente, a nenhum agrupamento, ficando, portanto, isolados. Por sua vez, os outros agrupamentos formados são: UFMG, UFPR e Unisinos; UERJ, UFRJ, UFPE, UFBA, Unifecap e USP-RP; e FURB e UFSC. O fato de a USP e a UFSC ficarem próximas converge com o achado na pesquisa de Souza et al. (2008). A aproximação da FURB com ambas, USP e UFSC, converge com a pesquisa de Nascimento e Beuren (2011).

O segundo método de cluster utilizado foi o vizinho mais próximo ou single linkage, em que, assim como o primeiro método, foram criados dendrogramas por meio das três medidas de distância. O primeiro dendrograma se refere à distância quadrática euclidiana, conforme demonstrado a seguir, no Gráfico 4: 
Gráfico 4 - Dendrograma resultante do método vizinho mais próximo e distância quadrática euclidiana

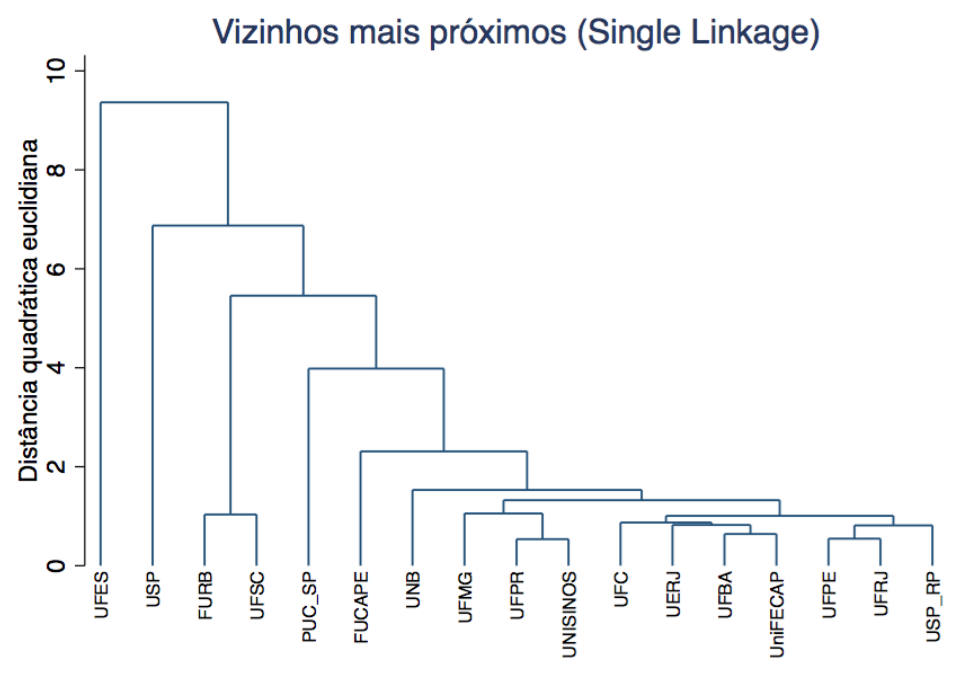

Fonte: os autores.

Percebe-se que o método vizinho mais próximo com a medida de distância quadrática euclidiana gera agrupamentos não tão distintos. Contudo, é possível observar que, ao se traçar uma reta um pouco abaixo do ponto 2, há a formação de oito agrupamentos, entre esses, a UFES, USP, PUC-SP, Fucape e UnB se apresentam de forma isolada. Por outro lado, os outros programas de pós-graduação se aglutinam em três grupos: FURB e UFSC; UFMG, UFPR e Unisinos; e UFC, UERJ, UFBA, Unifecap, UFRJ e USP-RP.

O Gráfico 5, a seguir, apresenta o dendrograma resultante do método vizinho mais próximo com a medida de distância Chebychev: 


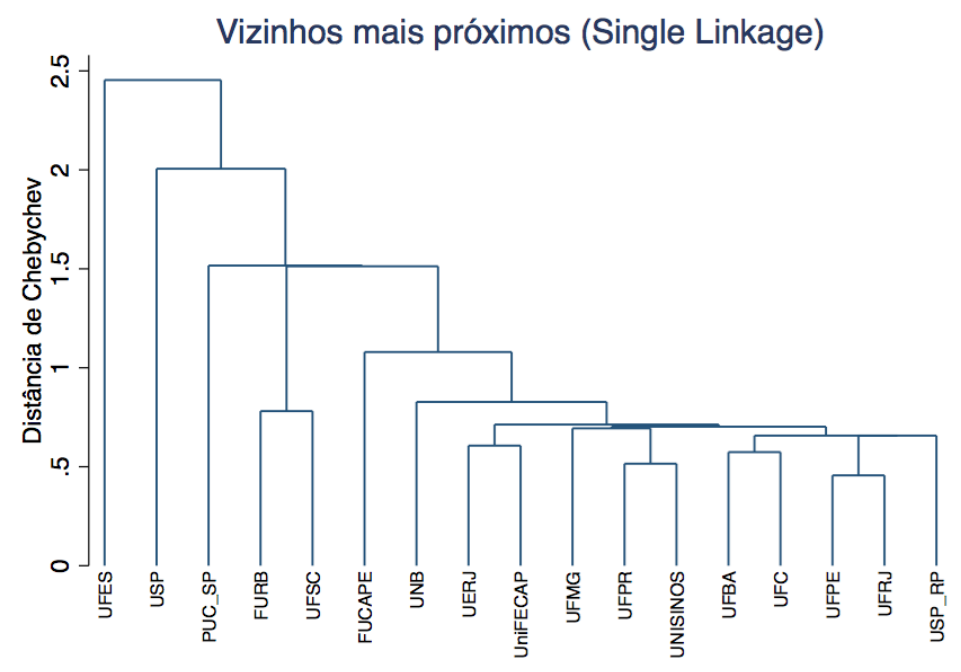

Fonte: os autores.

Assim como a medida de distância quadrática euclidiana, a medida de distância Chebychev cria clusters não tão distintos. Forma-se um único cluster que agrupa mais da metade dos programas de pós-graduação. Ao se traçar uma reta um pouco abaixo do ponto 1, há a formação de sete grupos. O maior grupo é composto pela UERJ, Unifecap, UFMG, UFPR, Unisinos, UFBA, UFC, UFPE, UFRJ e USP-RP. Por sua vez, o outro grupo formado é composto pela FURB e UFSC, e, por fim, UFES, USP, PUC-SP, Fucape e UnB ficam isoladas.

O último dendrograma do método vizinho mais próximo é demonstrado no Grafico 6, a seguir, e corresponde à distância Manhattan: 


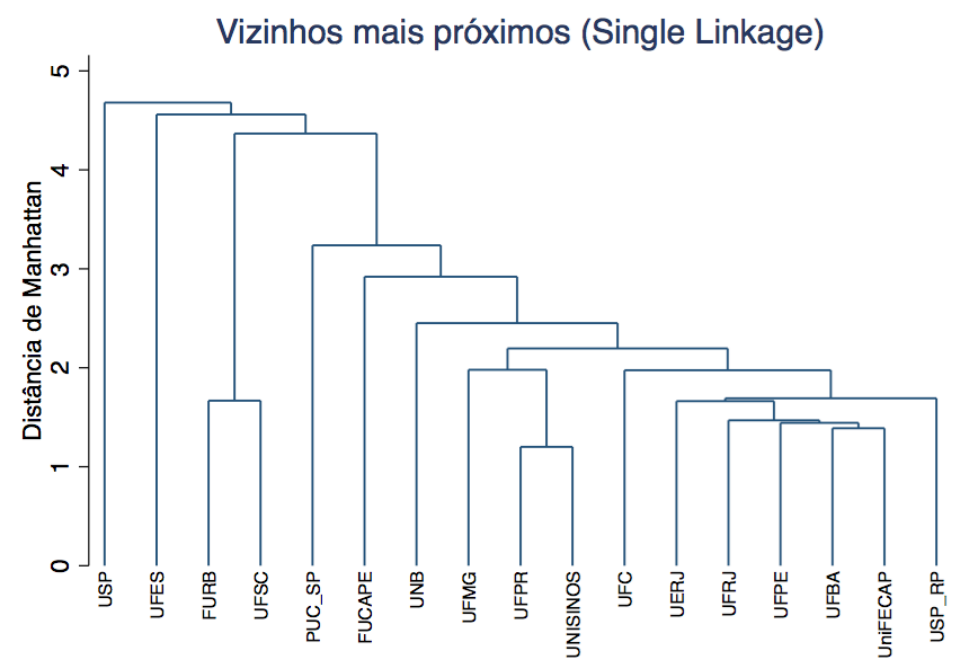

Fonte: os autores.

Diferente das duas distâncias anteriores, no método vizinho mais próximo com o uso da distância Manhattan, são apresentados clusters mais visuais, logo, de fácil identificação. Passando uma linha no ponto 2, são formados oito agrupamentos, dos quais, cinco são individuais e dizem respeito aos programas USP, UFES, PUC-SP, Fucape e UnB. Os outros três agrupamentos são: UFMG, UFPR e Unisinos; UFC, UERJ, UFRJ, UFPE, UFBA, Unifecap e USP-RP; e FURB e UFSC.

O terceiro método de agrupamento utilizado foi o vizinho mais distante ou complete linkage, e na sua execução foram adotadas três medidas de distâncias.

O Gráfico 7, a seguir, mostra o dendrograma para a distância quadrática euclidiana: 
Gráfico 7 - Dendrograma resultante do método vizinho mais distante e distância quadrática euclidiana

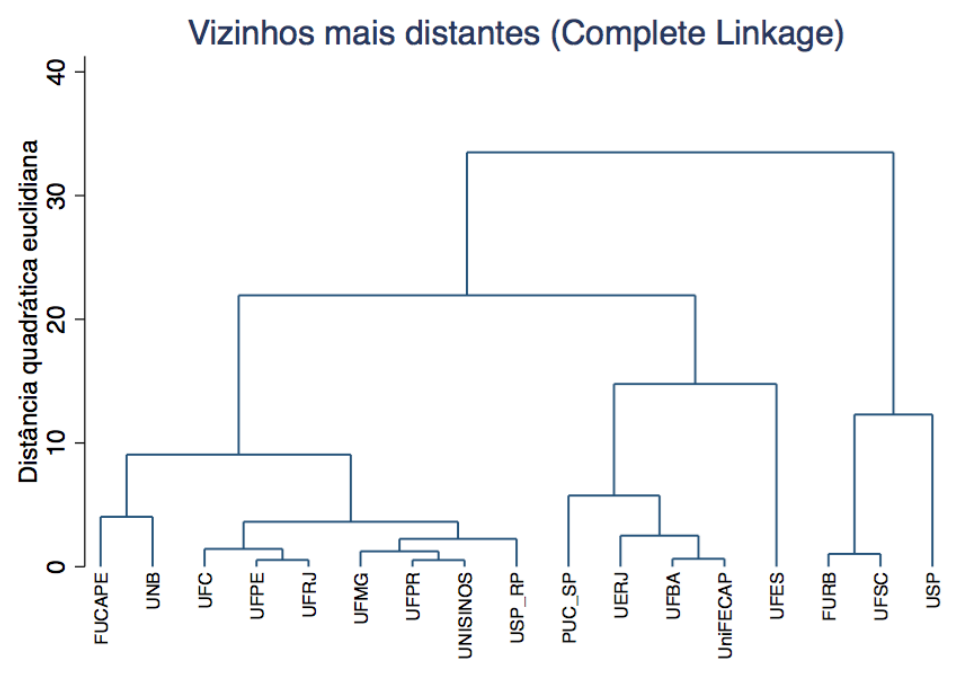

Fonte: os autores.

O método vizinho mais distante alinhado à distância quadrática euclidiana foi um dos mais eficientes para a formação de agrupamento, sendo gerados três agrupamentos distintos, como pode ser observado ao se traçar uma reta no ponto 20. O primeiro e maior agrupamento é composto pela Fucape, UnB, UFC, UFPE, UFRJ, UFMG, UFPR, Unisinos e USP-RP. O segundo agrupamento é formado pela PUC-SP, UERJ, UFBA, Unifecap e UFES. Finalmente, o terceiro e último agrupamento é composto pela FURB, UFSC e USP. Essa reunião entre os três programas foi também verificada nos estudos de Souza et al. (2008) e de Nascimento e Beuren (2011), como já comentado.

O Gráfico 8, a seguir, demonstra o dendrograma formado por meio do método vizinho mais distante com a medida de distância Chebychev: 
Gráfico 8 - Dendrograma resultante do método vizinho mais distante e distância Chebychev

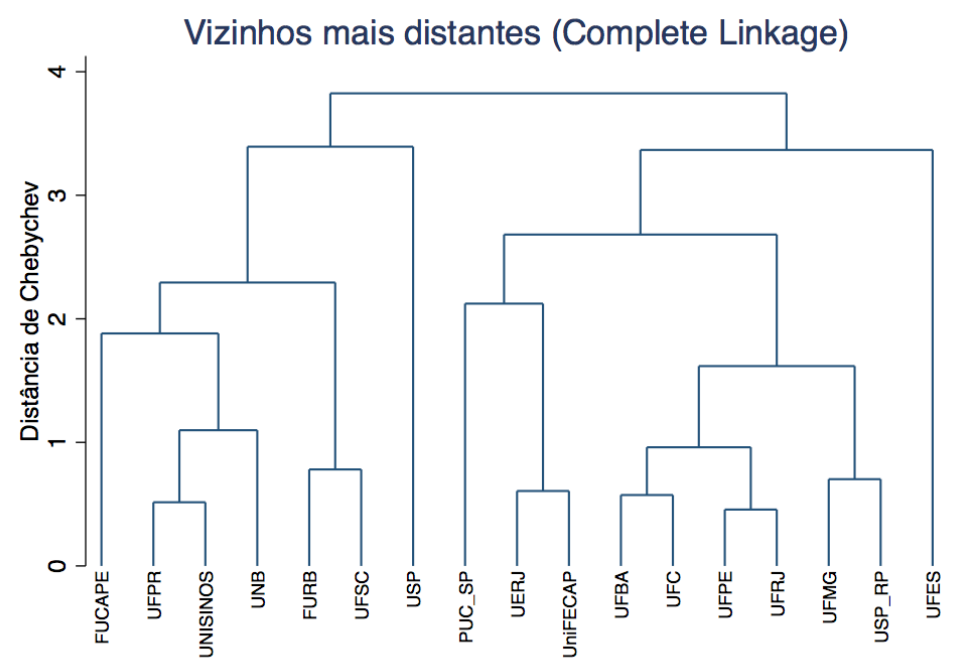

Fonte: os autores.

Por meio dessa distância foi possível formar cinco grupos de programas de pós-graduação em Contabilidade. Para tanto, foi necessário delinear uma reta entre os pontos 2 e 3. Dos grupos formados, apenas a USP e a UFES ficaram isoladas. Os outros grupos são: Fucape, UFPR, Unisinos, UnB, FURB e UFSC; PUC-SP, UERJ e Unifecap; e UFBA, UFC, UFPE, UFRJ, UFMG, USP-RP e UFES.

A última medida de distância aplicada ao método vizinho mais distante está apresentada no Gráfico 9, a seguir: 


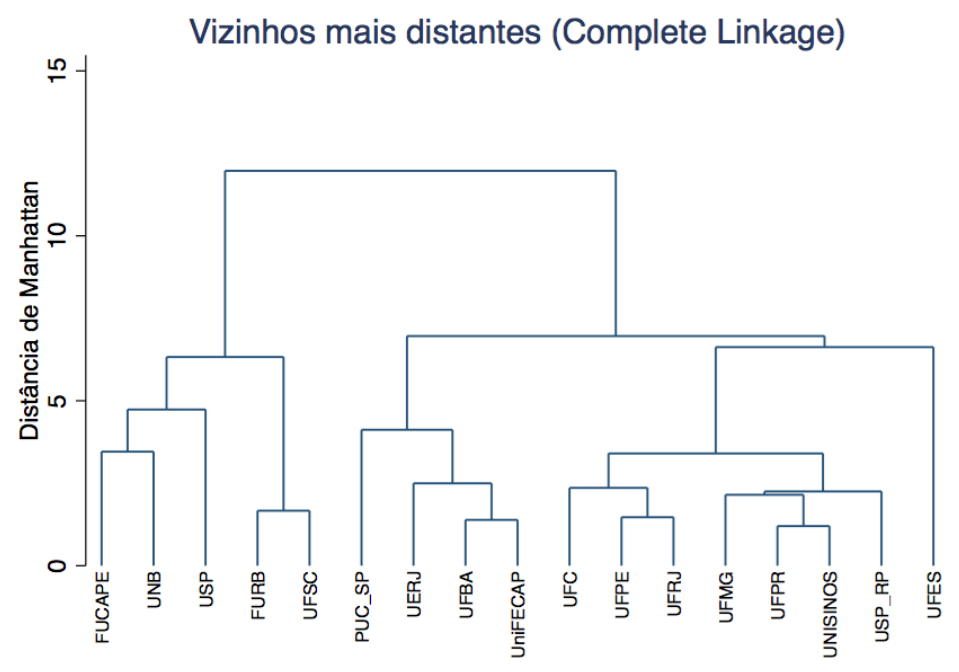

Fonte: os autores.

A medida de distância Manhattan no método vizinho mais distante proporcionou a formação de três clusters bem-definidos. O primeiro é formado pelos programas da Fucape, UnB, USP, FURB e UFSC. O segundo grupo é composto pelos programas da PUC-SP, UERJ, UFBA e Unifecap. O último grupo é constituído pela UFC, UFPE, UFRJ, UFMG, UFPR, Unisinos, USP-RP e UFES.

Percebe-se, por meio dos dendrogramas nos Gráficos 7, 8 e 9, que o método “vizinhos mais distantes” constituiu agrupamentos mais bem-definidos. Logo, é o método que melhor se aplica quando se busca a formação de grupos mais homogêneos em uma amostra. Além disso, demonstrou certa uniformidade, mesmo ao se utilizar outra medida de distância.

O quarto método de agrupamento utilizado foi o centroide e, como descrito anteriormente, para esse método é indicada apenas a utilização da distância quadrática euclidiana.

Desse modo, o Gráfico 10, a seguir, apresenta a combinação do método centroide e a distância quadrática euclidiana: 
Gráfico 10 - Dendrograma resultante do método centroide e distância quadrática euclidiana

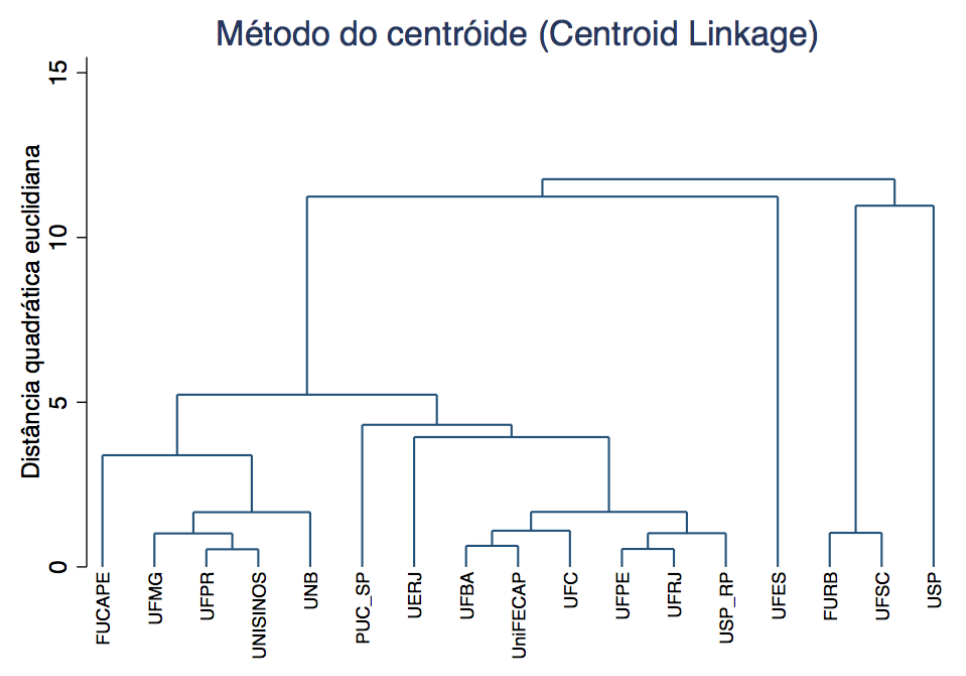

Fonte: os autores.

Nota-se que há a formação de cinco grupos bastante distintos quando é delineada uma reta no ponto 5. A USP e a UFES não se agruparam a nenhum outro programa de pós-graduação. Por sua vez, os outros agrupamentos são: Fucape, UFMG, UFPR, Unisinos e UnB; PUC-SP, UERJ, UFBA, Unifecap, UFPE, UFRJ e USP-RP; e FURB e UFSC. Como demonstrado em outros métodos, com medidas de distância diferentes, a USP e a UFES, em geral, formam um cluster independente.

O último dos métodos de agrupamento utilizados foi o Ward, e, assim como o método centroide, foi aplicada apenas a distância quadrática euclidiana: 
Gráfico 11 - Dendrograma resultante do método Ward e distância quadrática euclidiana

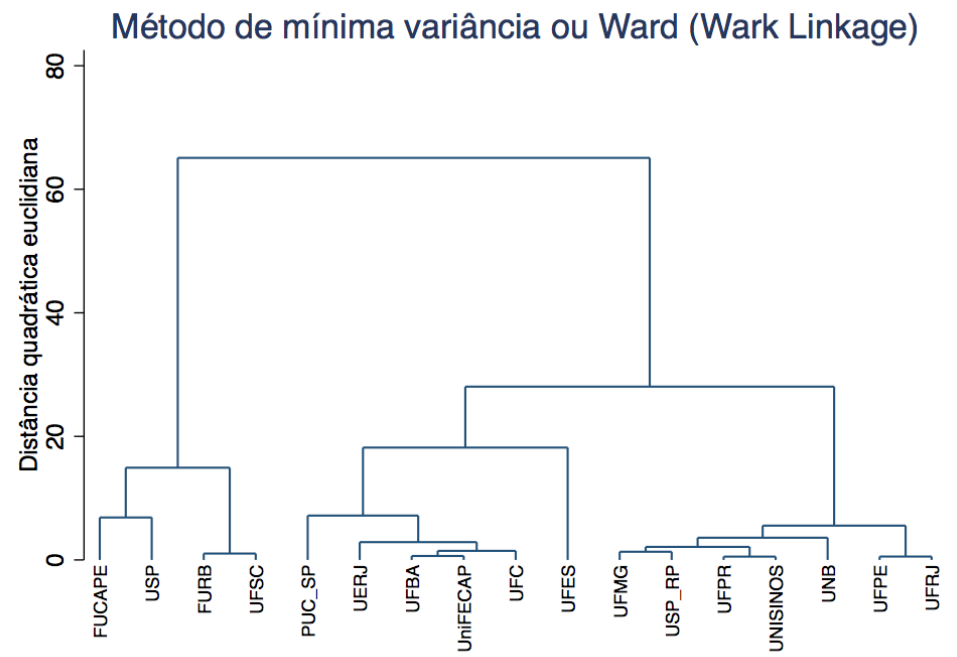

Fonte: os autores.

Junto ao método vizinhos mais distantes, o método Ward, por meio da distância quadrática euclidiana, são os mais eficientes para a elaboração de clusters. Foram criados três clusters nítidos ao se traçar uma reta no ponto 20. O primeiro cluster é composto pela Fucape, USP, FURB e UFSC. O segundo, pela PUC-SP, UERJ, UFBA, UniFecap, UFC e UFES. E o último cluster é constituído pela UFMG, USP-RP, UFPR, Unisinos, UnB, UFPE e UERJ.

A seguir, o Quadro 3 apresenta um comparativo dos resultados, para efeitos de análise:

Quadro 3-Quadro resumo com os agrupamentos obtidos

\begin{tabular}{|c|c|c|c|c|c|c|c|c|c|}
\hline Mod & $\mathbf{N}$ & 1 & 2 & 3 & 4 & 5 & 6 & 7 & 8 \\
\hline 1 & 5 & UFES & USP & $\begin{array}{l}\text { Fucape } \\
\text { UFMG } \\
\text { UFPR } \\
\text { Unisinos } \\
\text { UnB, } \\
\text { UFPE } \\
\text { UFRJ } \\
\text { USP-RP }\end{array}$ & $\begin{array}{l}\text { PUC-SP, } \\
\text { UERJ, } \\
\text { UFBA, } \\
\text { Unifecap } \\
\text { e UFC }\end{array}$ & $\begin{array}{l}\text { FURB e } \\
\text { UFSC }\end{array}$ & & & \\
\hline
\end{tabular}




\begin{tabular}{|c|c|c|c|c|c|c|c|c|c|}
\hline Mod & $\mathbf{N}$ & 1 & 2 & 3 & 4 & 5 & 6 & 7 & 8 \\
\hline 2 & 6 & UFES & USP & PUC-SP & $\begin{array}{l}\text { Fucape, } \\
\text { UFMG, } \\
\text { USP-RP, } \\
\text { UFPR, } \\
\text { Unisinos, } \\
\text { UnB }\end{array}$ & $\begin{array}{l}\text { UERJ, } \\
\text { Uni- } \\
\text { fecap, } \\
\text { UFBA, } \\
\text { UFC, } \\
\text { UFPE e } \\
\text { UFRJ }\end{array}$ & $\begin{array}{l}\text { FURB } \\
\text { e UFSC }\end{array}$ & & \\
\hline 3 & 8 & UFES & USP & Fucape & UnB & PUC-SP & $\begin{array}{l}\text { UFMG, } \\
\text { UFPR } \\
\text { e Unisi- } \\
\text { nos }\end{array}$ & $\begin{array}{l}\text { UERJ, } \\
\text { UFRJ, } \\
\text { UFPE, } \\
\text { UFBA, } \\
\text { Unife- } \\
\text { cap e } \\
\text { USP- } \\
\text {-RP }\end{array}$ & $\begin{array}{l}\text { FURB } \\
\text { e UFSC }\end{array}$ \\
\hline 4 & 8 & UFES & USP & Fucape & UnB & PUC-SP & $\begin{array}{l}\text { UFMG, } \\
\text { UFPR } \\
\text { e Unisi- } \\
\text { nos }\end{array}$ & $\begin{array}{l}\text { UFC, } \\
\text { UERJ, } \\
\text { UFBA, } \\
\text { Uni- } \\
\text { fecap, } \\
\text { UFRJ } \\
\text { e USP- } \\
\text {-RP }\end{array}$ & $\begin{array}{l}\text { FURB } \\
\text { e UFSC }\end{array}$ \\
\hline 5 & 7 & UFES & USP & Fucape & UnB & PUC-SP & $\begin{array}{l}\text { UERJ } \\
\text { Uni- } \\
\text { fecap } \\
\text { UFMG } \\
\text { UFPR, } \\
\text { Uni- } \\
\text { sinos } \\
\text { UFBA } \\
\text { UFC } \\
\text { UFPE } \\
\text { UFRJ } \\
\text { USP- } \\
\text {-RP }\end{array}$ & $\begin{array}{l}\text { FURB } \\
\text { UFSC }\end{array}$ & \\
\hline 6 & 8 & UFES & USP & Fucape & UnB & PUC-SP & $\begin{array}{l}\text { UFMG } \\
\text { UFPR } \\
\text { Unisi- } \\
\text { nos }\end{array}$ & $\begin{array}{l}\text { UFC } \\
\text { UERJ, } \\
\text { UFRJ } \\
\text { UFPE } \\
\text { UFBA } \\
\text { Uni- } \\
\text { fecap } \\
\text { USP- } \\
\text {-RP }\end{array}$ & $\begin{array}{l}\text { FURB } \\
\text { UFSC }\end{array}$ \\
\hline
\end{tabular}




\begin{tabular}{|c|c|c|c|c|c|c|c|c|c|}
\hline Mod & $\mathbf{N}$ & 1 & 2 & 3 & 4 & 5 & 6 & 7 & 8 \\
\hline 7 & 3 & $\begin{array}{l}\text { FURB } \\
\text { UFS } \\
\text { USP }\end{array}$ & $\begin{array}{l}\text { Fucape } \\
\text { UnB } \\
\text { UFC } \\
\text { UFPE } \\
\text { UFRJ } \\
\text { UFMG } \\
\text { UFPR } \\
\text { Uni- } \\
\text { sinos } \\
\text { USP- } \\
\text {-RP }\end{array}$ & $\begin{array}{l}\text { PUC-SP } \\
\text { UERJ } \\
\text { UFBA, } \\
\text { Unifecap } \\
\text { UFES }\end{array}$ & & & & & \\
\hline 8 & 5 & UFES & USP & $\begin{array}{l}\text { Fucape } \\
\text { UFPR } \\
\text { Unisinos } \\
\text { UnB, } \\
\text { FURB } \\
\text { UFSC }\end{array}$ & $\begin{array}{l}\text { PUC-SP } \\
\text { UERJ e } \\
\text { Unifecap }\end{array}$ & $\begin{array}{l}\text { UFBA } \\
\text { UFC } \\
\text { UFPE } \\
\text { UFRJ } \\
\text { UFMG } \\
\text { USPRP e } \\
\text { UFES }\end{array}$ & & & \\
\hline 9 & 3 & $\begin{array}{l}\text { UFC } \\
\text { UFPE } \\
\text { UFRJ } \\
\text { UFMG } \\
\text { UFPR } \\
\text { Uni- } \\
\text { sinos } \\
\text { US- } \\
\text { P-RP } \\
\text { UFES }\end{array}$ & $\begin{array}{l}\text { Fucape } \\
\text { UnB } \\
\text { USP } \\
\text { FURB } \\
\text { UFSC }\end{array}$ & $\begin{array}{l}\text { PUC-SP } \\
\text { UERJ } \\
\text { UFBA } \\
\text { Unifecap }\end{array}$ & & & & & \\
\hline 10 & 5 & UFES & USP & $\begin{array}{l}\text { Fucape } \\
\text { UFMG } \\
\text { UFPR } \\
\text { Unisinos } \\
\text { UnB }\end{array}$ & $\begin{array}{l}\text { PUC-SP } \\
\text { UERJ } \\
\text { UFBA } \\
\text { Unifecap } \\
\text { UFPE } \\
\text { UFRJ } \\
\text { USP-RP }\end{array}$ & $\begin{array}{l}\text { FURB } \\
\text { UFSC }\end{array}$ & & & \\
\hline 11 & 3 & $\begin{array}{l}\text { Fucape } \\
\text { USP } \\
\text { FURB } \\
\text { UFSC }\end{array}$ & $\begin{array}{l}\text { PU- } \\
\text { C-SP } \\
\text { UERJ } \\
\text { UFB } \\
\text { Uni- } \\
\text { fecap } \\
\text { UFC e } \\
\text { UFES }\end{array}$ & $\begin{array}{l}\text { UFMG } \\
\text { USP-RP } \\
\text { UFPR } \\
\text { Unisinos } \\
\text { UnB } \\
\text { UFPE } \\
\text { UERJ }\end{array}$ & & & & & \\
\hline
\end{tabular}

Fonte: os autores.

Posterior à utilização de diversos métodos de criação de agrupamentos e distintas medidas de distância, pode-se verificar que, em todos os métodos, a distância quadrática euclidiana apresenta a melhor formação de clusters. Portanto, esse seria 
um dos motivos de sua ampla utilização nas áreas da Contabilidade e da Administração, significando, então, uma medida de distância relevante quando se deseja encontrar semelhança e divergência entre programas de pós-graduação quanto às suas características.

\section{CONSIDERAÇÕES FINAIS}

O objetivo com a pesquisa foi identificar como se agrupam os programas de pós-graduação em Contabilidade, de acordo com as características da produção bibliográfica do triênio 2010-2012. Para isso, realizou-se uma série de simulações usando cinco métodos de agrupamentos, combinados com quatro medidas de distância.

Foi possível verificar que a maioria dos métodos apresentava agrupamentos similares, com variações em todos os casos. Quanto às semelhanças, observou-se que os programas de pós-graduação em Contabilidade da FURB e da UFSC, assim como os da UFPR e da Unisinos apresentaram similaridade em suas publicações, uma vez que esses programas se juntaram em clusters em todos os métodos e medidas de distância. Entende-se, por fim, que os docentes e discentes desses programas, em média, possuem o mesmo nível de produção acadêmica. Esse resultado pode indicar que os programas tendem a formar grupos de pesquisas para melhorar seus índices de produções, e, assim, auferir melhor pontuação frente à Capes, no quesito produção.

Quanto às divergências, foi perceptível que os programas de pós-graduação da USP, PUC-SP, Fucape e UFES estão, em geral, isolados. Logo, não se agrupam a outros programas. Esse resultado indica que as publicações desses programas se diferenciam das dos demais. Ressalta-se que era esperado que o programa da USP ficasse isolado dos demais, uma vez que é o programa de pós-graduação em Contabilidade mais antigo do Brasil, influenciando, assim, o fazer da pesquisa contábil brasileira.

Na pesquisa de Soares e Casa Nova (2015), a FURB, a UFSC e a USP mostraram uma associação que também foi recorrente na presente pesquisa. No entanto, na referida pesquisa, a UnB também se associava a essas três instituições, o que não se repetiu aqui. Portanto, percebe-se que os programas de pós-graduação em Contabilidade, do Sul do País, buscaram aliança com o programa mais antigo e de maior produtividade, o que, possivelmente, desencadeou em aumento de produção, em ambos os programas, e melhoria na nota dos programas frente à Capes. Os programas de pós-graduação da UFSC e da FURB melhoraram suas notas após o triênio 2010-2012, saindo da nota 4 para a nota 5. Logo, constata-se que as alianças são fundamentais para a melhoria das notas dos programas de pós-graduação em Contabilidade. 
Além disso, o resultado do estudo levanta a discussão sobre a quantidade versus a qualidade da produção dos programas de pós-graduação em Contabilidade. O Presidente do Fórum de Pró-reitores de Pesquisa e Pós-graduação (COORDENAÇÃO DE APERFEIÇOAMENTO DE PESSOAL DE NÍVEL SUPERIOR, 2017) versou, em um evento junto à Capes e à Associação Nacional dos Pós-Graduandos (ANPG), sobre o sistema de avaliação, discutindo que a avaliação é estruturada com base em parâmetros e indicadores quantitativos, incentivando os programas a uma prática produtivista, e não necessariamente com foco em maior qualidade. Esse comportamento pode resultar em produção aligeirada, portanto, com menor qualidade e baixo impacto.

Considerando os resultados da presente pesquisa, recomenda-se que os programas busquem realizar alianças, como se observa pela análise de cluster, que tenham como impacto não somente aumentar sua produção de forma quantitativa, mas também de forma qualitativa. Com isso, pode-se aumentar o impacto das pesquisas em Contabilidade, além de também descentralizar o processo de produção do conhecimento, apoiando a formação, assim, de novos centros de pesquisas, fora do eixo Sul-Sudeste.

Desse modo, esta pesquisa contribui com a discussão do uso de indicadores da produção bibliográfica para a avaliação da qualidade de programas de pós-graduação. Por trás desses indicadores, há uma racionalidade que foca em indicadores de produtos (número de publicações em revistas) e que pode afastar docentes e discentes da concentração de esforços no processo de pesquisa, e de alianças acadêmicas entre instituições com interesses semelhantes ou distintos.

Como sugestão para trabalhos futuros, recomenda-se que sejam simulados os diversos agrupamentos com inclusão/exclusão de variáveis. Também se sugere o uso de alguma técnica que possa tratar a multicolinearidade presente entre as variáveis, como a distância de Mahalanobis.

Quanto à discussão sobre os indicadores, uma possibilidade seria incluir outros indicadores em uma avaliação simulada, com ênfase no processo, como, por exemplo, existência de grupos de pesquisa, número e qualificação de membros, obtenção de financiamento de pesquisa, projetos de colaboração acadêmica interinstitucionais e entre programas, entre outros. 


\section{REFERÊNCIAS}

BRASIL. Decreto n. 29.741, de 11 de julho de 1951. Institui uma Comissão para promover a campanha nacional de aperfeiçoamento de pessoal de nível superior. Diário Oficial da União, Brasília, DF, 13 jul. 1951.

BRASIL. Lei n. 4.024, de 20 de dezembro de 1961. Fixa as Diretrizes e Bases da Educação Nacional. Diário Oficial da União, Brasília, DF, 27 dez. 1961.

CONSELHO FEDERAL DE EDUCAÇÃO. Parecer n. 977, de 03 de dezembro de 1965. Definição dos Cursos de Pós-Graduação. Documentação, Brasília, DF, n. 44, p. 67-86, 1965.

COORDENAÇÃO DE APERFEIÇOAMENTO DE PESSOAL DE NÍVEL SUPERIOR. Classificação da Produção Intelectual. 2014. Disponível em: <http://www. capes.gov.br/avaliacao/instrumentos-de-apoio/classificacao-da-producao-intelectual>. Acesso em: 11 jul. 2018.

COORDENAÇÃO DE APERFEIÇOAMENTO DE PESSOAL DE NÍVEL SUPERIOR. Competências. 2012. Disponível em: <http://www.capes.gov.br/acessoainformacao/80-conteudo-estatico/acesso-a-informacao/5418-competencias $>$. Acesso em: 11 jul. 2018.

COORDENAÇÃO DE APERFEIÇOAMENTO DE PESSOAL DE NÍVEL SUPERIOR. Planilhas de indicadores. 2013. Disponível em: <http://avaliacaotrienal2013.capes.gov.br/>. Acesso em: 28 jun. 2016.

CORRAR, L. J.; PAULO, E.; DIAS FILHO, J. M. Análise multivariada: para os cursos de administração, ciências contábeis e economia. São Paulo: Atlas, 2009.

ESPEJO, M. M. D. S. B. et al. Campo de pesquisa em Contabilidade: uma análise de redes sob a perspectiva institucional. Revista de Educação e Pesquisa em Contabilidade, v. 3, n. 2, p. 47-71, 2009.

FÁVERO, L. P. L.; BELFIORE, P. Análise de dados, técnicas multivariadas exploratórias. Rio de Janeiro: Elsevier, 2015.

FÁVERO, L. P. L.; BELFIORE, P. Manual de análise de dados: estatística e modelagem multivariada com Excel, SPSS e Stata. Rio de Janeiro: Elsevier, 2017. 
FÁVERO, L. P. L. et al. Análise de dados: modelagem multivariada para tomada de decisões. Rio de Janeiro: Elsevier, 2009.

HAIR JUNIOR, F. et al. Análise multivariada de dados. 6. ed. Porto Alegre: Bookman, 2009.

IGARASHI, D. C. C. et al. A qualidade do ensino sob o viés da avaliação de um programa de pós-graduação em contabilidade: proposta de estruturação de um modelo híbrido. Revista de Administração, São Paulo, v. 43, n. 2, p. 117-137, abr./jun. 2008.

LATTIN, J.; CARROLL, J. D.; GREEN, P. E. Análise de dados multivariados. São Paulo: Cengage Learning, 2011.

LINS, M. P. E.; ALMEIDA, B.; BARTHOLO JUNIOR, R. S. Avaliação de desempenho na pós-graduação, utilizando a Análise Envoltória de Dados: o caso da Engenharia de Produção. Revista Brasileira de Pós-Graduação, v. 1, n. 1, p. 41-56, jul. 2004.

LOESCH, C.; HOELTGEBAUM, M. Métodos estatísticos multivariados. São Paulo: Saraiva, 2012.

MALHOTRA, N. K. Pesquisa de marketing: uma orientação aplicada. 6. ed. Porto Alegre: Bookman, 2012.

MANLY, B. F. J. Métodos estatísticos multivariados: uma introdução. 3. ed. Porto Alegre: Bookman, 2008.

MINGOTI, S. A. Análise de dados através de métodos de estatística multivariada: uma abordagem aplicada. Belo Horizonte: Ed. UFMG, 2005.

MURCIA, F. C. S.; ROSA, C. A.; BORBA, J. A. Produção Científica em Ciências Contábeis: uma comparação entre a meta estabelecida pela CAPES e a publicação de artigos por parte dos docentes de Programas de Pós-Graduação. Contabilidade, Gestão e Governança, Brasília, DF, v. 16, n. 1, p. 68-81, jan./abr. 2013.

NASCIMENTO, S.; BEUREN, I. M. Redes sociais na produção científica dos programas de pós-graduação de ciências contábeis do Brasil. Revista de Administração Contemporânea, Brasília, DF, v. 15, n. 1, p. 47-66, jan./fev. 2011. 
OLIVEIRA, F. E. M. de. SPSS básico para análise de dados. Rio de Janeiro: Ciência Moderna, 2007.

OLIVEIRA NETO, J. D.; MELI, D. B. O perfil da colaboração nos periódicos contábeis nacionais: muitos one-timers e poucos continuants. Revista Contemporânea de Contabilidade, v. 8, n. 15, p. 151-176, 2011.

PELEIAS, I. R. Didática do ensino superior da contabilidade: aplicável a outros cursos superiores. São Paulo: Saraiva, 2006.

PELEIAS, I. R. et al. Evolução do ensino da contabilidade no Brasil: uma análise histórica. Revista Contabilidade \& Finanças, v. 18, p. 19-32, 2007. Edição Especial.

RIBAS, J. R.; VIEIRA, P. R. C. Análise multivariada com o uso de SPSS. Rio de Janeiro: Ciência Moderna, 2011.

ROCHA-E-SILVA, M. O Novo Qualis, que não tem nada a ver com a ciência do Brasil: carta aberta ao presidente da CAPES. Clinics, v. 64, p. 721-724, 2009.

SICSÚ, A. L. Análise de agrupamentos. São Paulo: Fundação Getúlio Vargas, 2004.

SILVA, H. A. S. et al. Programas de pós-graduação em contabilidade: análise da produção científica e redes de colaboração. Revista de Contabilidade e Organizações, Ribeirão Preto, v. 6, n. 14, p. 145-162, 2012.

SOARES, S. V.; CASA NOVA, S. P. C. A avaliação de programas da CAPES, os conceitos e o uso de indicadores bibliográficos. Revista Gestão Universitária na América Latina - GUAL, Florianópolis, v. 8, n. 2, p. 278-301, maio 2015.

SOARES, S. V.; CASA NOVA, S. P. C. O Qualis Reflete o Impacto dos Artigos de Revistas Brasileiras de Contabilidade? Revista de Gestão, Finanças e Contabilidade, v. 6, p. 6-23, 2016.

SOARES, S. V.; MÚRCIA, F. D. Ranking dos Programas de Pós-Graduação Acadêmicos em Contabilidade no Brasil, no triênio 2010-2012. Revista Catarinense da Ciência Contábil, Florianópolis, v. 15, n. 46, p. 74-87, set./dez. 2016. 
SOARES, S. V.; PFITSCHER, E. D. Doutorado em Contabilidade no Brasil: há espaço para expansão da oferta de cursos? Revista Brasileira de Contabilidade, v. 195, p. 67-82, 2012.

SOARES, S. V.; RICHARTZ, F.; MÚRCIA, F. Dal-Ri. Ranking da Pós-Graduação em Contabilidade no Brasil: Análise dos Programas de Mestrado com base na Produção Científica em Periódicos Acadêmicos no Triênio 2007-2009. Revista Universo Contábil, Blumenau, v. 9, n. 3, p. 55-74, jul./set. 2013.

SOUZA, F. C. et al. Análise das IES da área de Ciências Contábeis e de seus pesquisadores, por meio de sua produção científica. Contabilidade Vista \& Revista, v. 19, n. 3, p. 15-38, 2008.

\section{Como citar este artigo:}

\section{ABNT}

SOARES, Sandro Vieira et al. Programas de pós-graduação em Contabilidade: semelhanças e diferenças da produção bibliográfica. RACE, Revista de Administração, Contabilidade e Economia, Joaçaba: Ed. Unoesc, v. 17, n. 2, p. 695732, maio/ago. 2018. Disponível em: <http://editora.unoesc.edu.br/index.php/ race>. Acesso em: dia/mês/ano.

\section{APA}

Soares, S. V., Silva, V. P., Casa Nova, S. P. C., \& Góis, A. D. (2018). Programas de pós-graduação em Contabilidade: semelhanças e diferenças da produção bibliográfica. RACE, Revista de Administração, Contabilidade e Economia, 17(2), 695-732. Recuperado em dia/mês/ano, de http://editora.unoesc.edu.br/index.php/race 
